\title{
EFFECTIVENESS OF RECURVE WALLS IN REDUCING WAVE OVERTOPPING ON SEAWALLS AND BREAKWATERS
}

\author{
JON PEARSON, TOM BRUCE \\ School of Engineering \& Electronics, University of Edinburgh, The King's Buildings, \\ Edinburgh, EH9 3JL, Scotland, UK \\ WILLIAM ALLSOP \\ Univ. Southampton \& HR Wallingford, Howbery Park, Wallingford, Oxon, OX10 8BA \\ ANDREAS KORTENHAUS \\ Leichtweiss Institut, Technical University of Braunschweig, Beethoven Str 51A, 38106 \\ Braunschweig, Germany \\ JENTSJE VAN DER MEER \\ INFRAM, P.O. Box 16, 8316 ZG Marknesse, The Netherlands
}

\begin{abstract}
Designers of vertical seawalls and breakwaters have often included some form of seaward overhang (recurve / parapet / wave return wall / bullnose) as part of the structure with the design motivation of reducing wave overtopping by deflecting back seaward uprushing water. Despite a lengthy track record in the field and relevance to current design issues, very little generic guidance is available for their incorporation into seawall / breakwater design. This paper reports a study whose aim is the formulation of generic guidance for recurve structure design. Particular attention is given to high freeboard and / or wave breaking conditions under which the recurve / parapet gives very large reductions (recurve $k$-factor $<0.05$ ). The paper presents tentative guidance in the form of a decision chart. Finally, overtopping and loading results from a case study into a wall of particularly complex geometry are presented and compared with earlier studies. Forces on the vertical wall are found to be highly impulsive in nature and approximately double the magnitude of those expected on a simple wall, with additional forces of a similar magnitude measured on the underside of the parapet.
\end{abstract}

\section{Introduction}

For well over a century, designers of seawalls and breakwaters have often included some form of seaward overhang as part of the structure. This design feature is referred to variously as a recurve / parapet / wave return wall / bullnose. While arguably there are some distinctions to be made between these, they all share the design motivation of reducing wave overtopping by deflecting back seaward uprushing water (Figure 1). This design feature (for simplicity hereafter referred to as a recurve if it is curved, otherwise parapet) has many 
attractions, not least at a time when there is evidence of increased storm activity in many parts of the world placing increased pressure on the performance of existing coastal defence structures. For reasons of visual amenity, simply enhancing the performance of a wall against overtopping by increasing the crest level may not always be a satisfactory option - recurves offer an alternative.

With such a lengthy track record in the field and relevance to current design issues, it is surprising that very few systematic studies have been carried out and even less generic guidance offered for their incorporation into seawall / breakwater design.
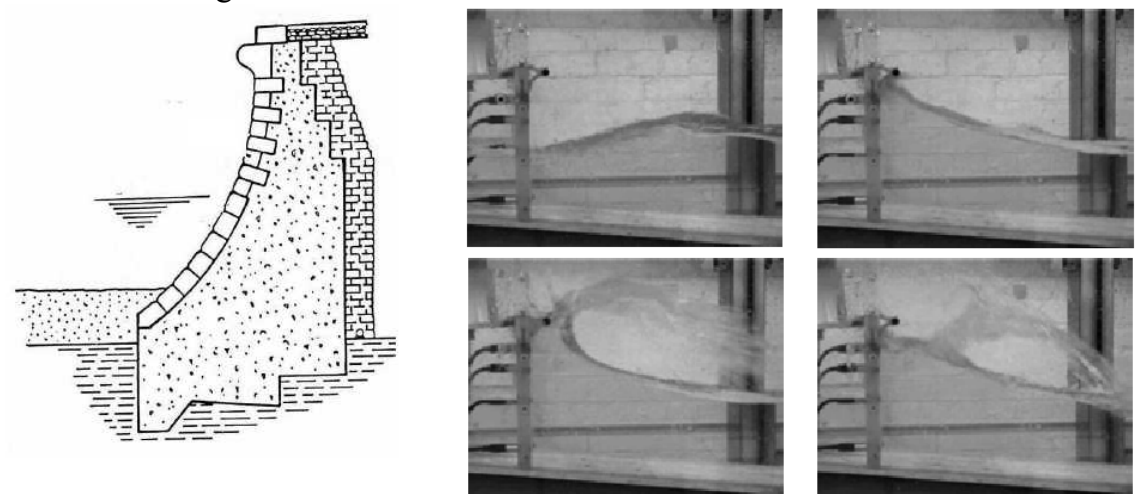

Figure 1. Left, a seawall with recurve. Right, a model recurve in the laboratory at Edinburgh.

This paper updates reporting of an on-going UK / German / Dutch collaborative study whose aim is the formulation of generic guidance for recurve / parapet structure design. It begins with a review of previous studies and a detailed reprise of initial project findings. Particular attention is then paid to modelling conditions (generally high freeboard and / or wave breaking) under which the recurve / parapet gives very large reductions (by greater than a factor of 20; ie recurve $k$-factor $<0.05$ ). Finally, overtopping and loading results from a case study into a wall of particularly complex geometry are presented and compared with earlier studies.

\section{Previous studies}

Systematic hydraulic model studies of wave overtopping date back to the 1970 s (eg Goda, 1971 \& 1975). Most work focussed upon simple sloping structures (eg Owen, 1980), later extended / modified to rubble mound structures and to steep and vertical walls (eg Franco et al, 1994 \& 1995; van der Meer \& Janssen, 1995; van der Meer et al 1998). For vertical walls, early studies were carried out under wave / structure combinations which gave few or no breaking waves at the wall. In the mid-90s it was realised that a transition to breaking or impulsive 
conditions at a wall caused a significant change in overtopping performance not predicted by existing methods. Recent investigations (eg Allsop et al, 1995; Bruce et al, 2001; Pearson et al, 2002; Napp et al, 2004) have focussed on these impulsive conditions and verified / expanded guidance on the subject. Current guidance includes the UK Environment Agency Overtopping Manual (Besley, 1999) and even more recently in The Netherlands, the TAW Manual (van der Meer, 2002).

Early studies of structures with some form of recurve include the work of Owen \& Steele (1991) and Juhl (1992). These studies offer overtopping reduction factors but are not generic in nature.

In Japan, a detailed research programme has investigated a non wave overtopping seawall (also known as a flaring shaped seawall, FSS). This type of structure has a large radius curve starting well below still water level whose radius changes with elevation. Results of regular wave tests and numerical simulations are given in Kamikubo et al (2000), with new irregular wave data being presented elsewhere at this conference (Yamashiro et al, 2004). The investigators demonstrated a reduction in required crest level of up to c. 30\%.

Cornett et al (1999) describe an extensive and systematic investigation of the influence of parapets on overtopping. The test programme included "chamfered" walls where the parapet was angled landward rather than overhanging seaward. For conventional seaward leaning parapets, reduction factors of ten or more are reported even for parapets inclined at angles as little as $30^{\circ}$. Helpful summary charts are presented with comparisons to standard formulae, but it is admitted that the overtopping response was found to be "highly variable" resulting quite some unresolved scatter.

Kortenhaus et al (2001) report on a series of tests in which overtopping and wave loading are measured for vertical walls with and without parapet. They found that the parapet is effective in reducing overtopping only under conditions where the relative crest freeboard $R_{d} / H_{S}>1.5$. Wave loading on the structure was found to be significantly increased by the presence of the parapet for lower freeboards, $R_{c} / H_{s}<1.2$, with factors of 2.0 and 1.7 being quoted for impulsive and non-impulsive waves respectively. This study, together with work in the UK under the Violent Overtopping by Waves at Seawalls (VOWS) project formed the starting point for the current investigation. First results were reported at the Coastal Structures '03 conference (Kortenhaus et al, 2003). These are summarised in the next section. 
3. Review of tentative generic method (Kortenhaus et al, 2003)

Analysis was carried out of overtopping measurements from a number of datasets which included a wide range of recurve / parapet types, plain and composite walls and impulsive and non-impulsive conditions at small and large scale. It was seen that some "with recurve" data fell as much as three orders of magnitude below the discharges measured (or expected) for the plain structure. The effectiveness of the recurve / parapet in reducing overtopping was quantified by the $k$-factor defined as

$$
k \equiv \frac{q_{\text {with_recurve }}}{q_{\text {without_recurve }}}
$$

Plotting $k$ against relative freeboard $R_{c} / H_{s}$ for each structure / recurve combination (example in Figure 2) suggested a three-regime predictor going from "little or no effect" to "very large reduction" regimes via a transition regime. The first regime extends to $R_{c} / H_{s}=R_{0}{ }^{*}$, with the transition to the third regime occurring at $R_{c} / H_{s}=m^{*}$. Equations for $k, R_{0}{ }^{*}$ and $m^{*}$ are as follows.

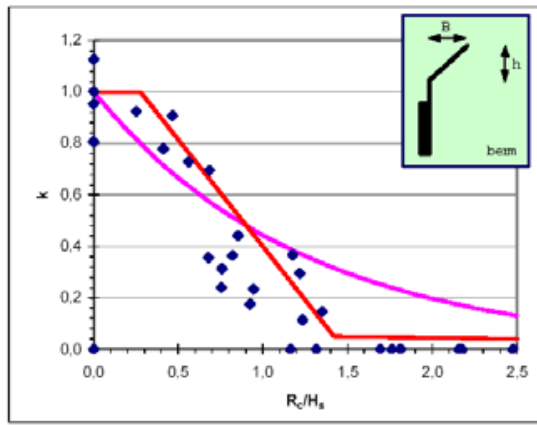

Figure 2. Recurve k-factor $v s$ relative crest freeboard (from Kortenhaus et al, 2003). The curve shows an earlier predictor (from Kortenhaus et al, 2001).

$$
k= \begin{cases}1.0 & \text { for } \frac{R_{c}}{H_{s}} \leq R_{0}^{*} \\ 1-\frac{1}{m}\left(\frac{R_{c}}{H_{s}}-R_{0}^{*}\right) & \text { for } R_{0}^{*}<\frac{R_{c}}{H_{s}} \leq R_{0}^{*}+m^{*} \\ k_{23}-0.01 \cdot\left(\frac{R_{c}}{H_{s}}-R_{0}^{*}-m^{*}\right) & \text { for } \frac{R_{c}}{H_{s}} \geq R_{0}^{*}+\mathrm{m}^{*}\end{cases}
$$

where $k_{23}$ is the $\mathrm{k}$-factor at which the lowest $\mathrm{k}$ regime begins ${ }^{\dagger}$ (set to $0.2^{\ddagger}$ ) and

\footnotetext{
${ }^{\dagger} k_{23}$ was referred to as $k_{3}$ in Kortenhaus et al (2003).

$\$$ The value of 0.2 is preferred to 0.05 used in Kortenhaus et al (2003).
} 


$$
\begin{gathered}
R_{0}^{*} \equiv 0.25 \cdot \frac{h_{r}}{B_{r}}+0.05 \frac{P_{c}}{R_{c}} \\
m \equiv 1.1 \sqrt{\frac{h_{r}}{B_{r}}}+0.2 \frac{P_{c}}{R_{c}} \quad m^{*} \equiv m\left(1-k_{23}\right)
\end{gathered}
$$

Applying this model for $k$ to the available dataset and plotting the dimensionless mean discharge adjusted by the $k$-factor against relative crest freeboard gave the graph in Figure 4. This k-factor approach gave a useful reduction in the scatter in the data, and showed that the adjusted data generally lay on the conservative side of van der Meer and Janssen (1995). However, there was quite some data which lay very much below the line, by up to a factor of 100. This is in line with the scatter observed in the lowest $k$ regime $\left(R_{c} / H_{s} \geq\right.$ $R_{0}{ }^{*}+m^{*}$ ). The study has since been extended to focus on this regime of largest reduction factors - the topic of the next section.

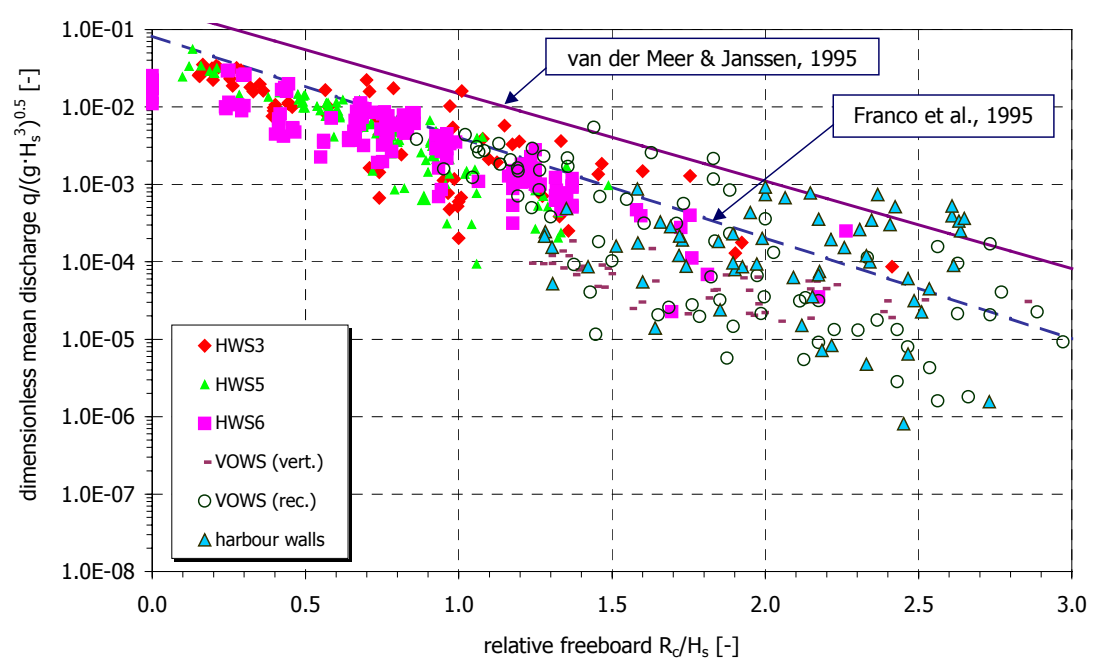

Figure 4. Non-dimensional mean overtopping discharge vs relative crest freeboard incorporating correction for reduction factor k (equation 1). From Kortenhaus et al (2003).

\section{High freeboard / low k cases}

The basis for this part of the study is a dataset consisting of 85 tests carried out at small-scale supplemented by five tests carried out under closely comparable conditions at large scale (at UPC Barcelona, see Pearson et al, 2002). That the lowest $k$ (largest reduction) regime of Kortenhaus et al (2003) performs generally conservatively but not particularly well for these tests is shown in Figure 5, where the measured k-factor is plotted against the value predicted. 


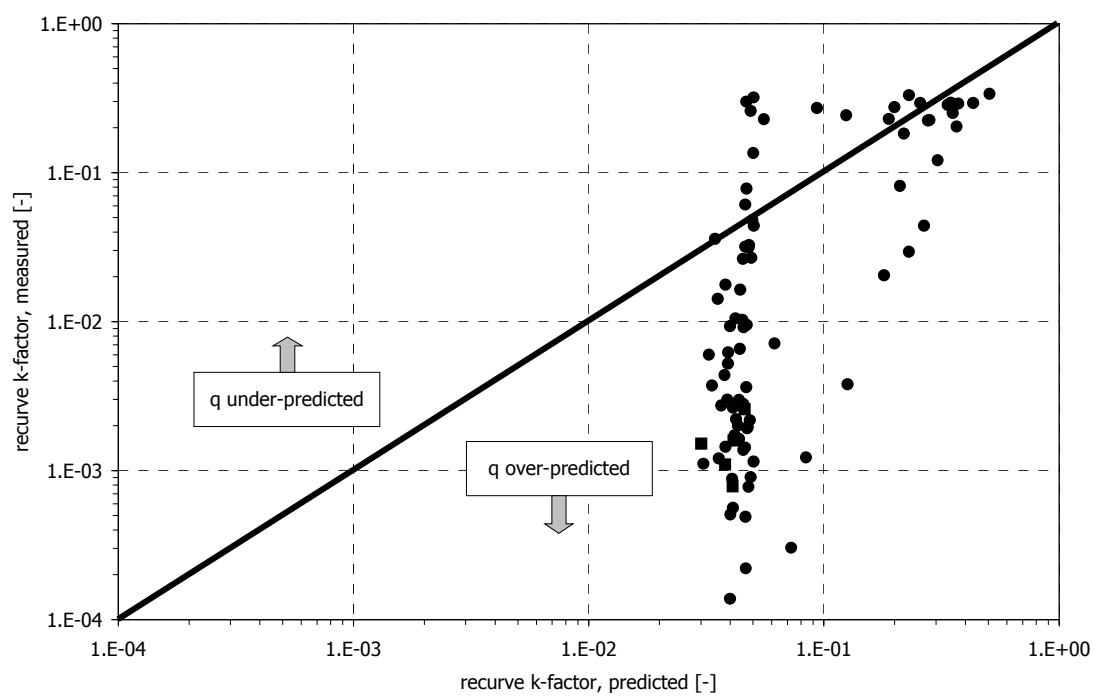

Figure 5. Measured $k$-factor $v s$ predicted, VOWS data. Circles are small-scale data ( 85 tests); squares are large-scale data (five tests). Note logarithmic axes.

Exploration of the dependency of $k$ upon key structural and wave parameters found some dependency upon both relative crest freeboard $(k \downarrow$ as $R_{c} / H_{s} \uparrow$ with quite some scatter) and upon the relative water depth at the base of the wall $\left(k \downarrow\right.$ as $h_{s} / H_{s} \downarrow$ again with quite some scatter). The dependency upon relative freeboard is explained by the observation that the higher the relative freeboard, the more vertically upward any uprushing water travels, and the more effectively this is thrown entirely seaward by the recurve. The relative depth dependency seems to rest upon the fact that the incident waves are increasingly likely to be breaking (or even broken) at the wall as this parameter decreases. Again, such conditions favour vertically thrown uprush and improved recurve efficiency.

Combining these to give $\mathrm{k}$ as a function of $R_{c} / H_{s} \times H_{s} / h_{s}=R_{c} / h_{s}$ reduces scatter somewhat and reveals some organised behaviour. Plotting the ratio of measured to predicted $\mathrm{k}$ (Figure 6), it would appear that an approach similar to that taken for all cases (Section 3) should be taken, with the response falling into three regimes;

1. $\quad R_{d} / h_{s} \leq 0.6 ; k$ as per Kortenhaus et al (2003);

2. $0.6<R_{c} / h_{s} \leq 1.1 ; k \rightarrow k \times 180 \exp \left(-8.5 R_{c} / h_{s}\right)$;

3. $R_{c} / h_{s}>1.1 ; k \rightarrow k \times 0.02$. 
The effectiveness of this adjustment to $k$ can be gauged from Figure 7, which plots the ratio of the measured to new predicted $k$-factors against dimensionless discharge. The data is now scattered around the ideal (ratio $=1$ ) line and all predictions fall within one order of magnitude of measurements.

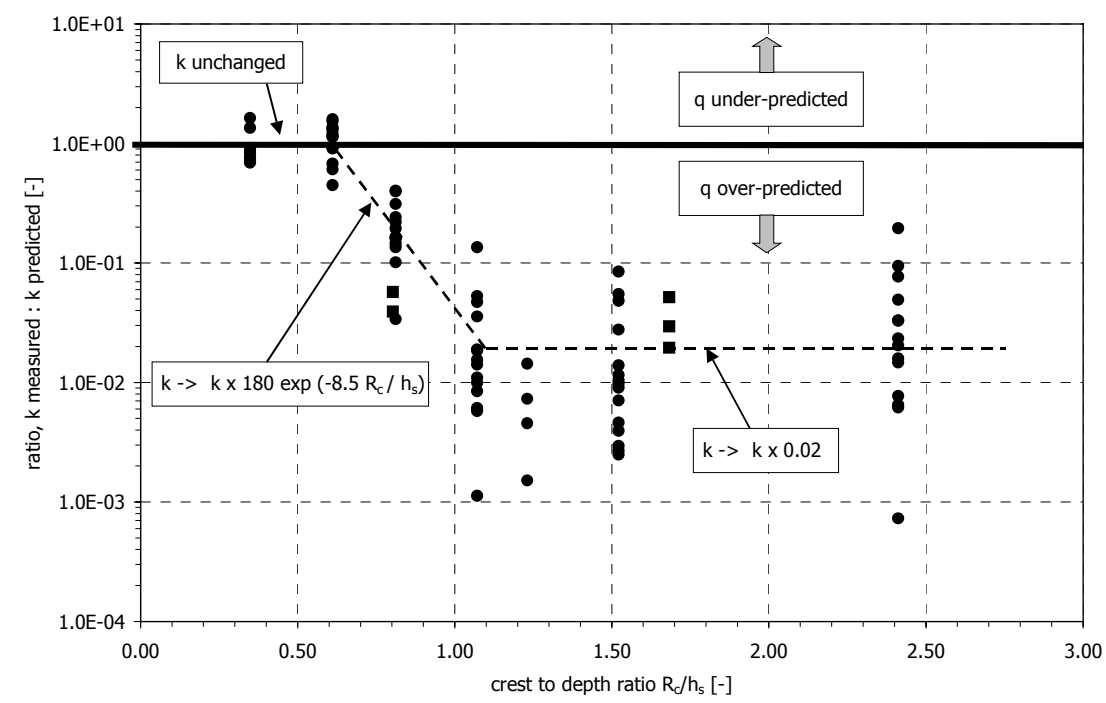

Figure 6. Ratio of $k$ measured to $k$ predicted by Kortenhaus et al (2003) plotted against crest to depth ratio. Lines show proposed three-regime adjustment.

It might be expected that scatter would be greatest for the very smallest discharges, and indeed this appears to be the case here (Figure 7). For nondimensional mean discharges $q>10^{-5}$, the scatter reduces to give agreement to with a factor of approximately two. The inherent scatter for the lowest discharges may mean that it is unlikely that $k$-factors of less than perhaps 0.05 could be safely realised in design, and certainly not without detailed physical model studies. The methodology is summarised in a decision chart (Figure 8).

\section{Promenade wall case study}

\subsection{Introduction}

This section reports results from a design study of an unusual seawall to defend against very long return period conditions. There are some important visual constraints on fixing the overtopping discharge by crest freeboard alone. Consideration instead is being given to a wall with parapet (Figure 9) whose crown deck will form a promenade. The purpose of the study was to determine a 
suitable parapet extension $B_{r}$ to limit overtopping to an admissible level under extreme conditions.

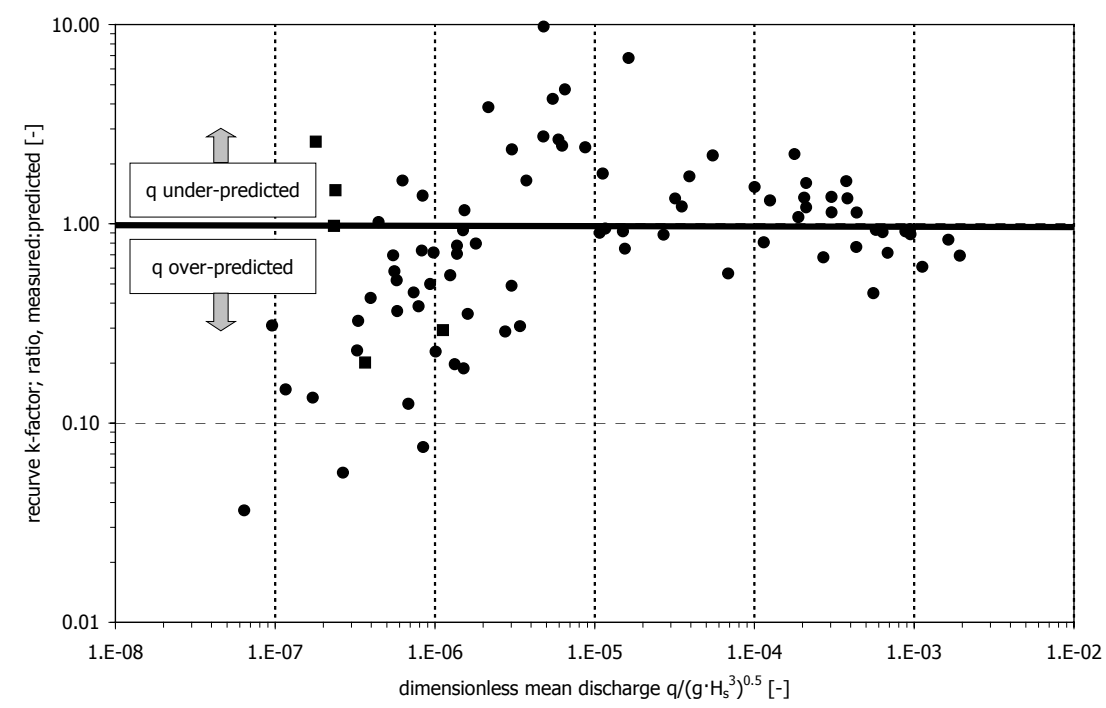

Figure 7. Ratio, measured:predicted $k$-factor plotted against non-dimensional overtopping rate.

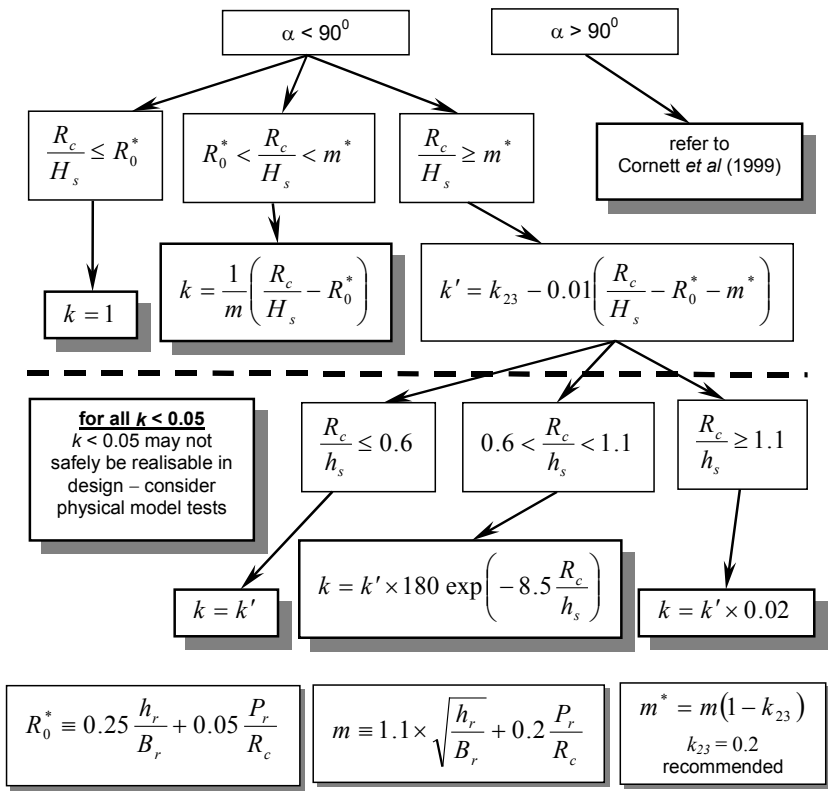

Figure 8. "Decision chart" summarising methodology for tentative guidance. 
It can be seen from the cross-sections that this problem presents difficulties for application of the method described in Sections 3 and 4. Firstly, the recurve does not reach up to the crest of the structure, leaving a problem of what is $h_{r}$. The parapet section also begins at an unusually low relative elevation, $P_{c}$. It was decided that a physical model study should be carried out. Three cross-sections were tested with increasing parapet overhangs, $B_{r}$. Pressure measurements were made on the vertical wall and on the underside of the overhanging parapet.
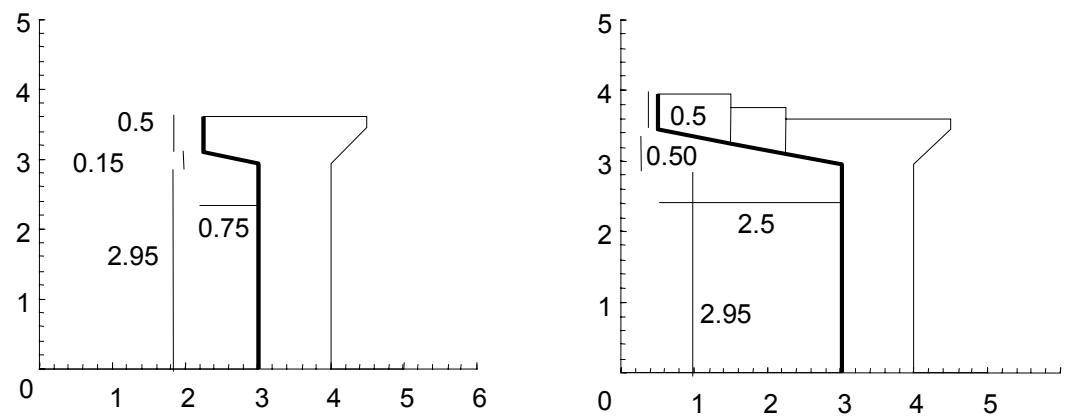

Figure 9. Left; the basic "small recurve" structure. Right; showing two added sections increasing parapet width $B_{r}$ ("medium recurve" and "large recurve"). Dimensions in $\mathrm{m}$ at prototype scale.

\subsection{Overtopping observations and measurements}

Tests were carried out in the wave channel at the University of Edinburgh. The channel is $20 \mathrm{~m}$ long by $0.4 \mathrm{~m}$ wide with a working water depth of $0.7 \mathrm{~m}$. The channel is equipped with an absorbing flap-type wave paddle. Overtopping discharge was collected in a tank suspended from a load cell. Pressure measurements were taken using seven Druck PDCR 800 pressure transducers (natural frequency $28 \mathrm{kHz}$ ) sampled at $2 \mathrm{kHz}$. The test matrix included both uniand bi-modal seas with nominal steepnesses around 0.04 and 0.02 .

With a relatively small gap between still water level and the underside of the parapet, some particularly violent behaviour was observed, as incoming waves filled the gap under the parapet (Figure 10).

The overtopping results are shown in Figure 11. It is immediately striking that the mean discharge does not show as strong an influence from the parapet overhang $B_{r}$ as the influence of steepness. Indeed, the overtopping response of these structures was seen to be very sensitive to wave period, with the shorter period waves generally more affected by the presence of the parapet than the longer waves. Observations show that these longer waves are more capable of filling the under-parapet gap and then overflowing this filled volume to overtop. 


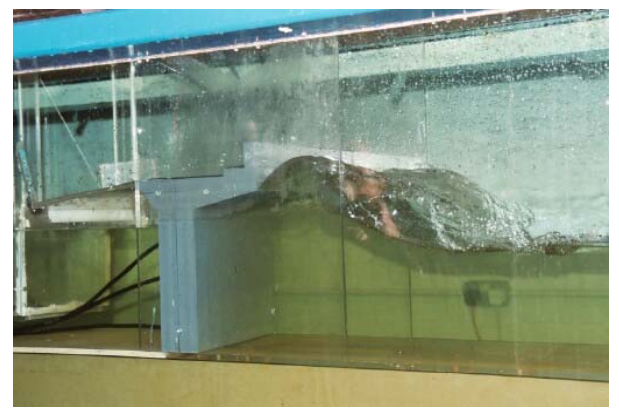

Figure 10. Example of a wave being deflected seaward in the promenade wall study

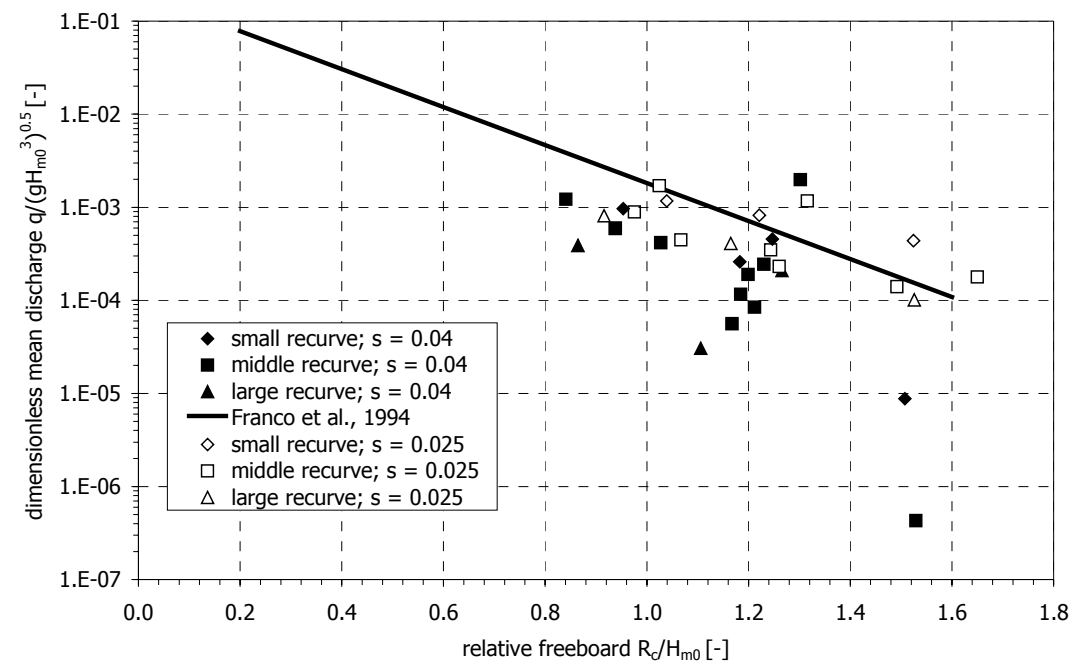

Figure 11. Graph of relative mean overtopping rate $v s$ relative freeboard; all cross-sections. The only $s=0.04$ point lying above the line corresponds to a bi-modal sea for which the definition of steepness is less physically meaningful.

For completeness, a comparison of these measurements with the tentative generic method was made. Making the assumption that the parapet can be modelled as an average line from its base to the crest of the structure, overtopping was generally under-predicted by factors of up to ten. This reinforces the argument that this is a complex configuration with wave-structure interactions and resultant overtopping performance strongly affected by the parapet lying so close to still water level. 


\subsection{Loadings on parapet}

It is clear from fundamental momentum considerations that a structure deflecting water through a greater angle must experience enhanced loadings, but how these are distributed (and thus the effect on overturning moments) is not well understood. Kortenhaus et al (2001) give horizontal load increase factors of 1.7 and 2.0 for non-impulsive and impulsive conditions respectively. The upward loads on the parapet are reported as being of a similar magnitude.

The results of the force measurements are summarised in Table 1, together with comparator forces from a Delft Hydraulics study. The forces have been non-dimensionalised in the conventional manner. The "upwards" force is the force acting normal to the underside of the parapet.

Table 1. Dimensionless forces measured on promenade wall, plain vertical wall comparison.

\begin{tabular}{|c|c|c|}
\hline dimensionless force, $\mathbf{F} / \mathbf{\rho g H}_{\mathbf{m} \mathbf{0}}{ }^{\mathbf{2}}$ & Horizontal [-] & Upwards, on parapet [-] \\
\hline plain vertical wall (den Heijer, 1998) & $9.3-11.4$ & \\
\hline promenade wall, small recurve & 17.2 & 16.3 \\
\hline promenade wall, medium recurve & 20.5 & 21.1 \\
\hline
\end{tabular}

Thus, for this parapet configuration structure, measured horizontal forces are higher than for a plain wall by factors $k_{F} \approx 2$, with further comparable (or even slightly larger) forces acting on the underside of the parapet. These factors are very much in line with those reported by Kortenhaus et al (2001).

Impulsive loads on a parapet are of some importance as the parapet structure is likely to have a higher natural frequency than the main part of the wall and thus may be able to "feel" and respond to the impulsive part of the loading to a greater extent. Observations of these tests suggested some highly impulsive loads, supported by very abrupt and loud slamming noises being heard repeatedly. Mean rise time measured at model scale was $2.0 \mathrm{~ms}( \pm 1.1$ $\mathrm{ms})$, with mean total impact duration $7.2 \mathrm{~ms}( \pm 2.7 \mathrm{~ms})$.

\section{Conclusions}

Kortenhaus et al (2003) presented a generic method for the prediction of the reduction in overtopping due to recurves / parapets. Quite some scatter remained for the largest reductions (smallest $k$-factors). This paper has presented an extended method with focus on this regime. The method builds upon a dependency of recurve effectiveness upon the crest to depth ratio $R_{c} / h_{s}$. The combined prediction method is summarised in a "decision chart".

Results from a physical model study of a "promenade wall" with unusual parapet have been presented, illustrating the difficulty in applying a generic method to complex structures (in this case, one with parapet unusually close to 
still water level). The model study showed that for this structure, overtopping reduction due to the parapet was more strongly influenced by wave period than by the parapet overhang, $B_{r}$.

Basic momentum considerations require that the presence of a recurve / parapet must increase the total load. Measurements of horizontal and upward loading on the "promenade wall" gave load horizontal increase factors $\left(k_{F}\right)$ of around two as compared to loads on a simple vertical wall. Upward loads on the underside of the parapet were of a similar magnitude (indeed greater in some cases). These findings were in line with those of Kortenhaus et al (2001). Very short-duration impulsive (slamming) loads were measured as the gap under the parapet filled. Parapets may be particularly able to respond to (and be damaged by) such loads.

\section{Acknowledgements}

The authors gratefully acknowledge the work of Helge Holtorf who performed and analysed the model tests at LWI at an early stage of the project. The authors' international collaboration has been facilitated by the EC FP5 "CLASH" project (EVK3-2001-0058).

\section{References}

Allsop, N.W.H., Besley, P. and Madurini, L. 1995. Overtopping performance of vertical and composite breakwaters, seawalls and low reflection alternatives. Proc. final MCS project workshop, Alderney, pub. University of Hannover.

Besley, P. 1999. Overtopping of seawalls - design and assessment manual. R\&D Technical Report W 178, Environment Agency, UK (ISBN 185705069 X)

Bruce, T., Allsop, N.W.H. and Pearson, J. 2001. Violent overtopping of seawalls extended prediction methods, Proc. "Breakwaters, coastal structures and coastlines", pp 245-256, Thomas Telford, London (ISBN 072773042 8)

Cornett, A., Li, Y. and Budvietas, A. 1999. Wave overtopping at chamfered and overhanging vertical structures. Proc. Intl. workshop on natural disasters by storm waves and their reproduction in experimental basins, Kyoto, Japan.

Den Heijer, F. 1998. Golfoverslag en krachten op verticale waterkerings-constructies. WL | delft hydraulics report H2014 (in Dutch)

Franco, L., de Gerloni, M. and van der Meer, J.W. 1994. Wave overtopping on vertical and composite breakwaters, Proc 24th Int. Conf. Coastal Eng., pp1030-1045 (ISBN 0-7844-0089-X)

Franco, L., de Gerloni, M. and van der Meer, J.W. 1995. Wave overtopping on vertical and composite breakwaters. Proc. final MCS project workshop, Alderney, pub. University of Hannover 
Goda, Y. 1971. Expected rate of irregular wave overtopping of seawalls. Coastal Engineering in Japan, Vol 14, pp 45-51, JSCE, Tokyo.

Goda, Y., Kishira, Y. and Kamiyama, Y. 1975. Laboratory investigation on the overtopping rates of seawalls by irregular waves. Ports \& Harbour Research Institute, vol 14, no. 4, pp 3-44, PHRI, Yokosuka.

Juhl, J. 1992. Investigations on the effect of structural measures on wave impact forces and overtopping. Proc. $3^{\text {rd }}$ project workshop, MAST I G6-S, Hannover, Germany (pub. University of Hannover)

Kamikubo, Y., Murakami, K. Irie, I. and Hamasaki, Y. 2000. Study on practical application of a non-wave overtopping type seawall. Proc $27^{\text {th }}$ Intl. Conf Coastal Eng, pp2215-2228 (ISBN 0-7844-0549-2)

Kortenhaus, A. Haupt, R. and Oumeraci, H. 2001. Design aspects of vertical walls with steep foreland slopes. Proc Breakwaters, coastal structures and coastlines, London (ICE), pp 221-232 (ISBN 0-7277-3042-8)

Kortenhaus, A., Pearson, J., Bruce, T., Allsop, N.W.H. and van der Meer, J.W. 2003. Influence of parapets and recurves on wave overtopping and wave loading of complex vertical walls. To appear in Proc "Coastal Structures '03" (ASCE)

Napp, N., Pearson, J., Bruce, T. and Allsop, N.W.H. 2004. Overtopping of seawalls under oblique wave attack and at corners. To appear in Proc. $29^{\text {th }}$ Int. Conf. Coastal Engineering (ASCE)

Owen, M.W. 1980. Design of seawalls allowing for overtopping. Report EX924, Hydraulics Research, Wallingford, UK.

Owen, M.W. and Steele, A.A.J. 1991. Effectiveness of re-curved wave return walls. Report SR 261, HR Wallingford, Wallingford, UK.

Pearson, J., Bruce, T., Allsop, N.W.H. and Gironella, X. 2002. Violent wave overtopping - measurements at large and small scale. Proc. $28^{\text {th }}$ Int. Conf. Coastal Engineering, pp 2227-2238, (ASCE) (ISBN 981238238 0)

Van der Meer, J.W. 2002. Technical report on wave run-up and wave overtopping at dikes. Report of the TAW, Technical Advisory Committee on Water Defences, The Netherlands

Van der Meer, J.W. and Janssen, J.P.F.M. 1995. Wave run-up and wave overtopping at dikes. Wave Forces on Inclined and Vertical wall Structures, pp 1-26, ed. Kobayashi N. \& Demirbilek Z., ASCE (ISBN 0-7844-0080-6)

Van der Meer, J.W., Tonjes, P. \& de Waal, J.P. 1998. A code for dike height design and examination. Proc. Coastlines, Structures \& Breakwaters '98 (ICE), pp 5-21, pub. Thomas Telford, London

Yamashiro, M., Yoshida, A. and Irie, I. 2004. Development of non wave-overtopping type seawall in deepwater. To appear in Proc $29^{\text {th }}$ Intl. Conf. Coastal Eng. (ASCE) 